\title{
Age, Growth, Reproduction and Fecundity of the Sharpsnout Seabream (Diplodus puntazzo Walbaum, 1792) in the Black Sea Region
}

\author{
Mehmet Aydın ${ }^{1, *}\left(\mathbb{D}\right.$, Çağrı Özdemir ${ }^{1} \mathbb{D}$ \\ ${ }^{1}$ Ordu University, Fatsa Faculty of Marine Science, Türkiye
}

\section{How to cite}

Aydın, M., Ozdemir, C. (2022). Age, Growth, Reproduction and Fecundity of the Sharpsnout Seabream (Diplodus puntazzo Walbaum, 1792) in the Black Sea Region. Turkish Journal of Fisheries and Aquatic Sciences, 22(5), TRJFAS19462. http://doi.org/10.4194/TRJFAS19462

\section{Article History}

Received 25 June 2021

Accepted 19 December 2021

First Online 21 December 2021

\section{Corresponding Author}

Tel.: +905424356280

E-mail: maydin69@hotmail.com

\section{Keywords}

Sharpsnout seabream

Diplodus puntazzo

Growth

Population parameters

Reproduction

\begin{abstract}
In this study, the Sharpsnout Seabream (Diplodus puntazzo) population parameters (age, sex composition, length-weight relationship (LWR), age-length relationship, growth parameters, condition factor, gonadosomatic index, reproductive) of the sharpsnout seabream (Diplodus puntazzo) in the southern Black Sea Region have been investigated. In the study carried out between April 2018 and March 2019, 276 sharpsnout seabream were sampled and the average length and weight were calculated as $30.0 \mathrm{~cm}$ and $463.9 \mathrm{~g}$, respectively. Male and female ratio was determined as 1:1.32 ( $P>0.05)$. Age of fish varied between $0-9$ years. The von Bertalanffy growth parameters were $L_{\infty}=48.1 \mathrm{~cm}, \mathrm{k}=0.2656$ year $^{-1}$ and $\mathrm{t}_{0}=-1.6587$ year for all individuals. The LWR was found as $W=0.0399 \mathrm{~L}^{2.7212}$ for all individuals. Total mortality rate $(\mathrm{Z}=0.560)$, natural mortality rate $(\mathrm{M}=0.501)$ and fishing mortality rate $(\mathrm{F}=0.059)$, growth performance index $\left(\phi^{\prime}=2.73\right)$ and condition factor value $(K=1.55)$ were calculated. The maximum GSI value was 6.83 in September. Mean relative fecundity was calculated as 14695.4 eggs / $1 \mathrm{~g}$. The mean egg diameter was calculated as 486.83 $\mu \mathrm{m}$. This study is very important in terms of being the first study on this species in the Black Sea and will provide a source for future studies.
\end{abstract}

\section{Introduction}

A member of the family Sparidae, the Sharpsnout Seabream (Diplodus puntazzo, Walbaum, 1792) is a valuable species that naturally disperses in the Eastern Atlantic Ocean, along the coast of South Africa, the Mediterranean, the Aegean Sea, and the Black Sea. Due to the warming of global water temperatures, it continues to spread along the European coasts of the Atlantic (Vinagre et al., 2010). It is among the common species of the Mediterranean, Aegean and Sea of Marmara (Russell et al., 2014). Although in the coastal areas with rocky habitats, it lives at depths of 0-150 m, it is commonly found at depths of 0-20 m (Jardas, 1996). Juveniles are commonly found in river mouths, estuaries or lagoons.

Though they can grow up to a maximum length of $60 \mathrm{~cm}$, they are mostly around $30 \mathrm{~cm}$ (Fischer et al., 1987). Like other Sparidae species, they are hermaphrodite. Young individuals are male, and after maturity, they transform into females. The reproduction occurs at the end of summer, early autumn (Pajuelo et al., 2008). Sharpsnout seabream is a high-value demersal species. It is sold for 8-10 USD per $\mathrm{kg}$ at the 
Black Sea markets (observations of Dr. Mehmet AYDIN). The average production in Turkey for the last ten years was 10.2 tons (TUIK, 2018)

There is little study on the species natural populations. The studies that were conducted in the Mediterranean Sea in recent years mainly focus on the species aquaculture (Boglione et al., 2003). In addition, Ventura et al. (2015) on requitment, Mouine et al. (2012) on the reproduction biology, Favaloro and Mazzola (2003; 2006) and Yıldırım et al. (2014) on the species skeletal anomalies, and Çoban et al. (2012) and Altın et al. (2015) studied feeding and growth performance under aquaculture. Its European populations were studied by Palma and Andrade (2002), and its genetic structure was studied by Bargelloni et al. (2005). Although there are some studies on the natural populations of this species in the Mediterranean Sea, the only study done in the Black Sea is by Aydın and Sağlam (2019). In this study, it was reported that the species feeds on rapana eggs. There is no study on the population structure of the species in the Black Sea.

In this study, it was aimed to examine the population parameters (age, length-weight relationship, sex composition, age-length relationship, growth parameters, condition factor, GSI and reproduction biology) of sharpsnout seabream that inhabits SinopHopa, the Black Sea. The study is very important from the point of its contribution to literature and science in terms of being the first study conducted in the Black Sea and containing the data necessary for sustainable management of the species.

\section{Materials and Methods}

In the study carried out between April 2018 and March 2019, 276 sharpsnout seabream were sampled with trammel nets with different mesh sizes (inner mesh $50,60,70$ and $80 \mathrm{~mm})$ at different depths $(0-20 \mathrm{~m})$ from the southern Black Sea Region (between Sinop and Hopa) (Figure1).

Captured fish were preserved in iceboxes for examination in the laboratory. Total length ( $T L$, in nearest $0.1 \mathrm{~cm})$, total wet weight $(\mathrm{W})$ and gonad wet weight (GW) (at $0.01 \mathrm{~g}$ precision) of all specimens were recorded. The sex of each specimen was determined by examining the gonads macroscopically.

The total length-weight relationship (LWRs) of the fish was calculated by applying the exponential regression equation $\mathrm{W}=\mathrm{aTL} \mathrm{L}^{\mathrm{b}}$, where $a$ and $b$ are constants (Ricker, 1975). The total length-weight relationships were examined separately as female, male, and all. Pauly's $t$-test (1984) was used to compare the " $b$ " values of male and female groups (Pauly, 1984). Age was estimated by scales removed from the left anterodorsal of fish. Scale preparation for aging was done according to the method by Chugunova (1963).

\section{Growth Parameters}

The von Bertalanffy growth equation (VBGE) was used to describe the growth of sharpsnout seabream for the whole sampled population (King, 1995; Sparre \& Venema, 1992). The Von Bertalanffy growth parameters

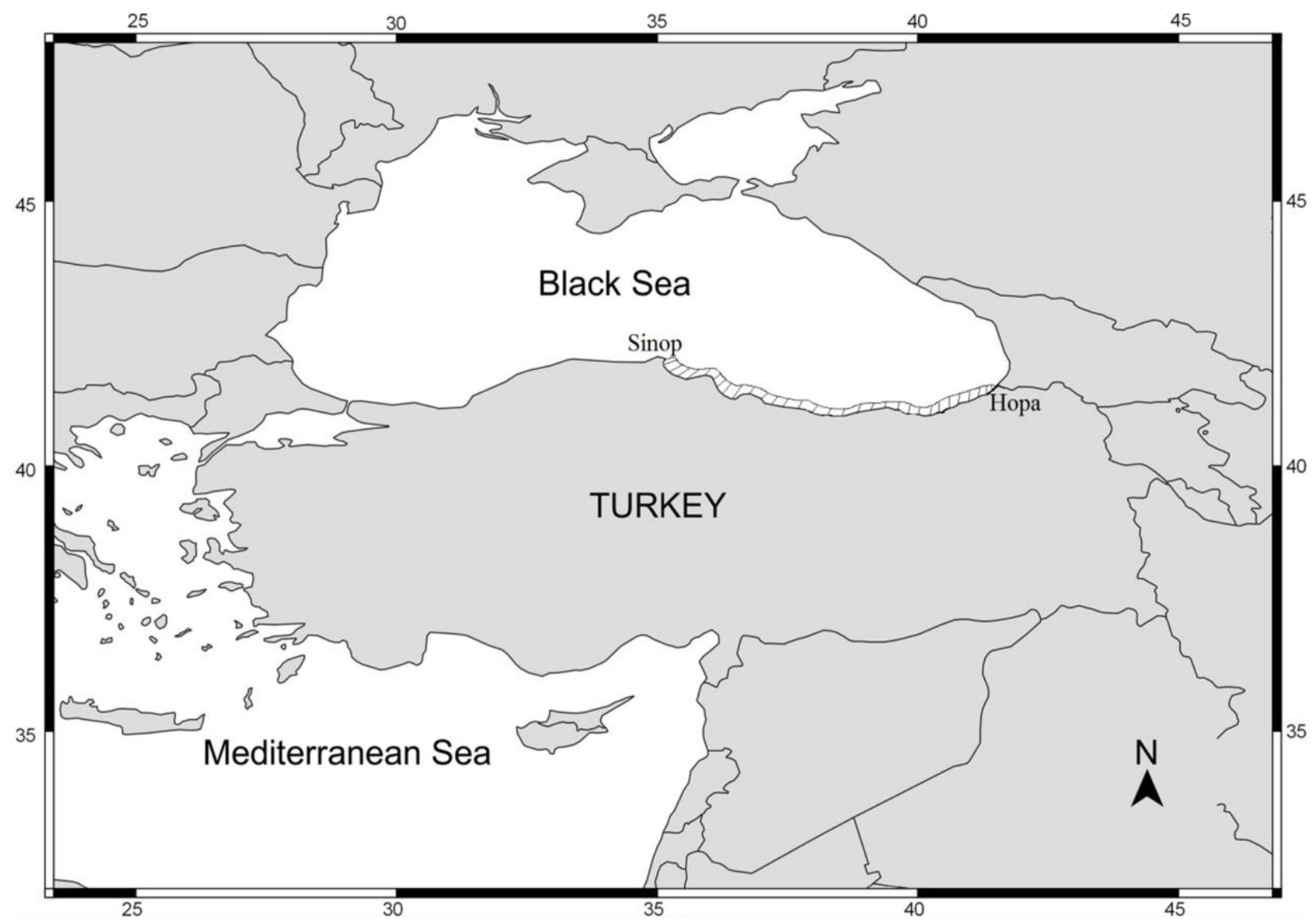

Figure 1. Study area 
$\left[L_{\infty}=a /(1-b) ; k=-\operatorname{Ln} b\right.$ and $\left.t_{0}=t+(1 / k) * \operatorname{Ln}\left(1-\left(L_{t} / L_{\infty}\right)\right)\right]$ were determined using at age-length data and the growth were estimated by using the Von Bertalanffy function: $L_{(t)}=L_{\infty}\left(1-e^{-k(t-t o)}\right)$, where $L_{t}$ is the total length at age $t, L_{\infty}$ is the asymptotic length, $k$ is the growth coefficient, and $t_{0}$ is the theoretical age when the fish would have been at zero total length (King, 1995; Sparre \& Venema, 1992).

The growth performance was determined using the growth index $\left(\phi^{\prime}=\log (k)+2 * \log \left(L_{\infty}\right)\right) \quad$ (Sparre \& Venema, 1987; King, 1995).

\section{Condition Factor}

In this research, the condition factor of Sharpsnout seabream was calculated monthly with no female and male grouping. Fulton's coefficient of condition factor (C) was calculated by $\mathrm{C}=\left(\mathrm{W} / \mathrm{TL}^{3}\right) \times 100$ (Ricker, 1975).

\section{Gonadosomatic Index}

Monthly values of the gonadosomatic index were calculated for each sex. GSI=(GW/W)*100 (De Vlaming et al., 1982).

\section{Fecundity}

The total fecundity was calculated by enumeration of the eggs obtained from the female samples in September when the GSI reached its highest value. Individuals used for egg counting were processed on the day they were caught, and the egg counts and measurements were performed on the same day after their gonads were removed. In order to determine total fecundity, 28 mature ovaries were examined. The number of eggs obtained from the ovaries and the subsamples taken from the front, middle, and rear parts of the hydrated oocytes were counted using the gravimetric method and calculated according to the following formula (Holden \& Raitt, 1974): $F=\frac{G}{g} * n$, where $F$ is the total number of eggs in the ovary, $G$ is ovary weight $(\mathrm{g}), \mathrm{g}$ is the weight of the subsample taken from the ovary $(\mathrm{g})$, and $\mathrm{n}$ is the total number of eggs (including previtellogenic oocytes) in the ovary taken from the subsample but only mature oocytes are taken into account while measuring egg diameters.

\section{Mortality Rates}

Decreases in stocks take place through two different kinds of deaths. These deaths are natural mortality rate $(\mathrm{M})$ and fishing mortality rate $(\mathrm{F})$. The sum of the two gives the instantaneous total mortality rate (Z). Z was calculated by using the survival rate (S). Survival rate is defined as the ratio of the number of fish surviving at the end of a certain period to the number of fish at the beginning of the period (Ricker, 1975), and it is calculated according to the following equation:
$S_{(t)}=\frac{N_{(t+1)}}{N_{(t)}}$ where $\mathrm{N}_{(\mathrm{t})}$ is the number of fish in the related age group and $\mathrm{N}_{(\mathrm{t}+1)}$ is the number of fish in the related age group at the end of one year. In this equation, the relation between the survival rate and the total mortality rate is as follows:

$$
S_{(t)}=e^{-Z(t)}
$$

Total mortality rate $(Z)$ is calculated as follows:

$$
Z=-\ln (S)
$$

Natural mortality $(\mathrm{M})$ is calculated according to Pauly (1980).

$$
\begin{gathered}
\log M=-0.0066-0.279 \log L_{\infty}+0.6543 \log k \\
+0.463 \log T
\end{gathered}
$$

Here, $T$ is the CTD derived average annual water temperature of the environment in which the Sharpsnout seabream lives (으).

\section{Results}

\section{Length-frequency Distribution}

The sampled 276 individual's length-frequency distribution was done with $2 \mathrm{~cm}$ intervals (Figure 2).

When the length-frequency distribution was examined the highest number of individuals was observed in 31-32 cm length group, with $19.64 \%$ (Figure 2). The $58.91 \%$ of the whole sampling belongs to the $29-36 \mathrm{~cm}$ length group. During the monthly samplings, the highest number of individuals were obtained in October (Table 1).

The smallest measured individual was measured $15.3 \mathrm{~cm}$ and the largest $45.4 \mathrm{~cm}$. In terms of weight, the smallest was $50.59 \mathrm{~g}$ and the heaviest was $1186.48 \mathrm{~g}$. Samples' monthly length-frequency distribution is given in Figure 3.

\section{Sex Composition}

During the study, $55.80 \%$ (154) of the sampled individuals were identified as female, $42.39 \%$ (117) as male, and $1.18 \%(5)$ as hermaphrodite (Table 2 ). The sex ratio was estimated at 1:1.2 (Table 2 ). The difference between sex ratios were found statistically significant $\left(\chi^{2}=5.052, d f=1, P>0.05\right)$.

\section{Length-weight Relationship}

Statistically, no difference was observed between the male individual's average length $(30.3 \mathrm{~cm} \pm 5.64)$ and female average length $\quad(30.5 \quad \mathrm{~cm} \pm 5.54) \quad(P<0.05)$ (Table 3).

The smallest hermaphrodite individual's length was measured to be $22.7 \mathrm{~cm}$, the largest $25.6 \mathrm{~cm}$, the 


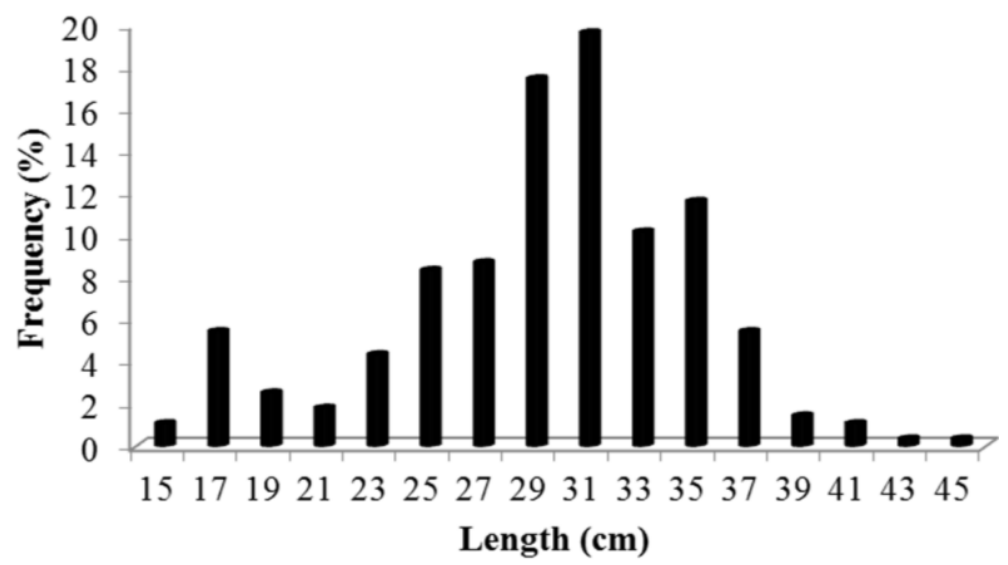

Figure 2. Total length-frequency distribution

Table 1. Number of sampled individuals per months

\begin{tabular}{lcccccccccccc}
\hline Months & Jan. & Feb. & Mar. & Apr. & May. & jun. & Jul. & Agu. & Sep. & Oct. & Nov. & Dec. \\
\hline Number & 2 & 8 & 34 & 8 & 12 & 24 & 8 & 25 & 22 & 106 & 18 & 9 \\
\hline
\end{tabular}
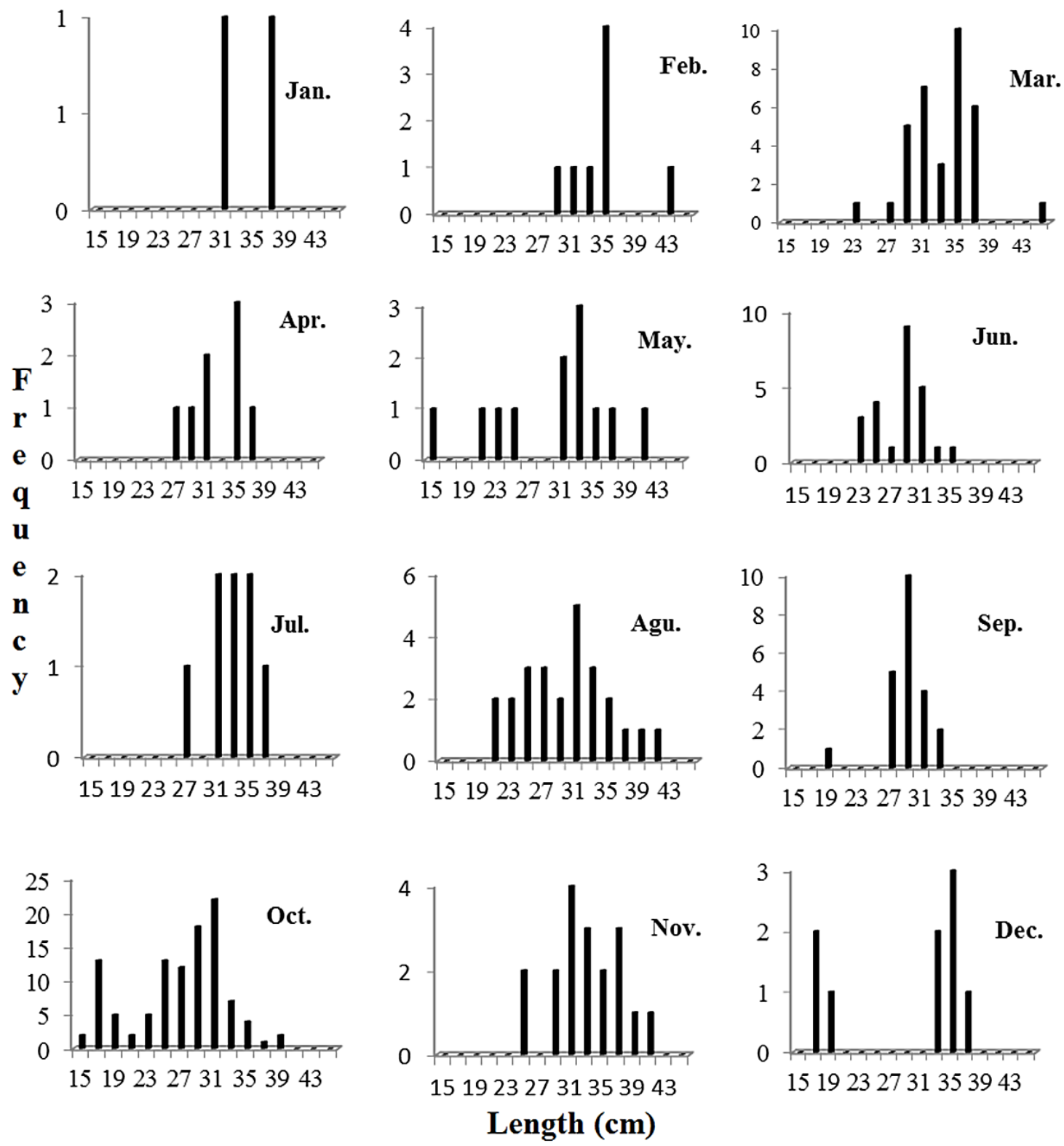

Figure 3. Monthly total length-frequency distributions 
average length as $24.12 \mathrm{~cm} \pm 1.28$, and all were estimated as age 1.

Male, female and overall sharpsnout seabreams were estimated to show negative allometry $(b<3)$ (Figure 4).

\section{Age Composition}

Age composition of the samples were estimated to be between age 0 and 9 . A large portion of the population (39.13\%) was in age 2 group (Table 4 ). In the study, 18 individuals were estimated to be age 0 , and the smallest individual was $15.3 \mathrm{~cm}$ (Figure 5). No individual smaller than this was obtained. Probably the mesh size of the net that was used during the study was not able to catch individuals smaller than this size, as a result, smaller than this size were not sampled.

\section{Growth and Mortality}

The von Bertalaffy growth parameters and growth equations of overall samples are given in Table 5 .

Table 2. Monthly sex ratio data

\begin{tabular}{|c|c|c|c|c|c|}
\hline \multirow{2}{*}{ Months } & \multicolumn{2}{|c|}{$\mathbf{N}$} & \multicolumn{2}{|c|}{ Chi-square } & \multirow[t]{2}{*}{$\mathbf{P}$} \\
\hline & Female & Male & (M:F) & $\left(x^{2}\right)$ & \\
\hline Jan. & 1 & 1 & $1: 1$ & 0 & $P<0.05$ \\
\hline Feb. & 4 & 4 & $1: 1$ & 0 & $P<0.05$ \\
\hline Mar. & 22 & 12 & $1: 1.83$ & 2.94 & $P<0.05$ \\
\hline Apr. & 4 & 4 & $1: 1$ & 0 & $P<0.05$ \\
\hline May. & 6 & 6 & 1:1 & 0 & $P<0.05$ \\
\hline Jun. & 17 & 7 & $1: 2.43$ & 4.167 & $P>0.05$ \\
\hline Jul. & 5 & 3 & $1: 1.66$ & 0.5 & $P<0.05$ \\
\hline Agu. & 9 & 16 & $1.77: 1$ & 1.96 & $P<0.05$ \\
\hline Sep. & 15 & 7 & $1: 2.14$ & 2.909 & $P<0.05$ \\
\hline Oct. & 49 & 52 & $1.06: 1$ & 0.089 & $P<0.05$ \\
\hline Nov. & 16 & 2 & $1: 8$ & 10.889 & $P>0.05$ \\
\hline \multirow[t]{2}{*}{ Dec. } & 6 & 3 & $1: 2$ & 1 & $\mathrm{P}<0.05$ \\
\hline & 154 & 117 & $1: 1.32$ & 5.052 & $P>0.05$ \\
\hline Total & 271 (+ 5 Herma & & & & \\
\hline
\end{tabular}

Table 3. Length and weight relationship parameters

\begin{tabular}{|c|c|c|c|c|c|c|}
\hline & \multicolumn{3}{|c|}{$\mathrm{L}(\mathrm{cm})$} & \multicolumn{3}{|c|}{$W(g)$} \\
\hline & Avg. $\pm S E$ & Min. & Max. & Avg. $\pm S E$ & Min. & Max. \\
\hline All & $30.3 \pm 5.59$ & 15.3 & 45.4 & $463.9 \pm 214.4$ & 50.6 & 1186.5 \\
\hline Female & $30.5 \pm 5.54$ & 16.9 & 45.4 & $475.5 \pm 212.3$ & 88.4 & 1095.8 \\
\hline Male & $30.3 \pm 5.64$ & 15.3 & 44.5 & $458.3 \pm 217.1$ & 50.6 & 1186.5 \\
\hline
\end{tabular}

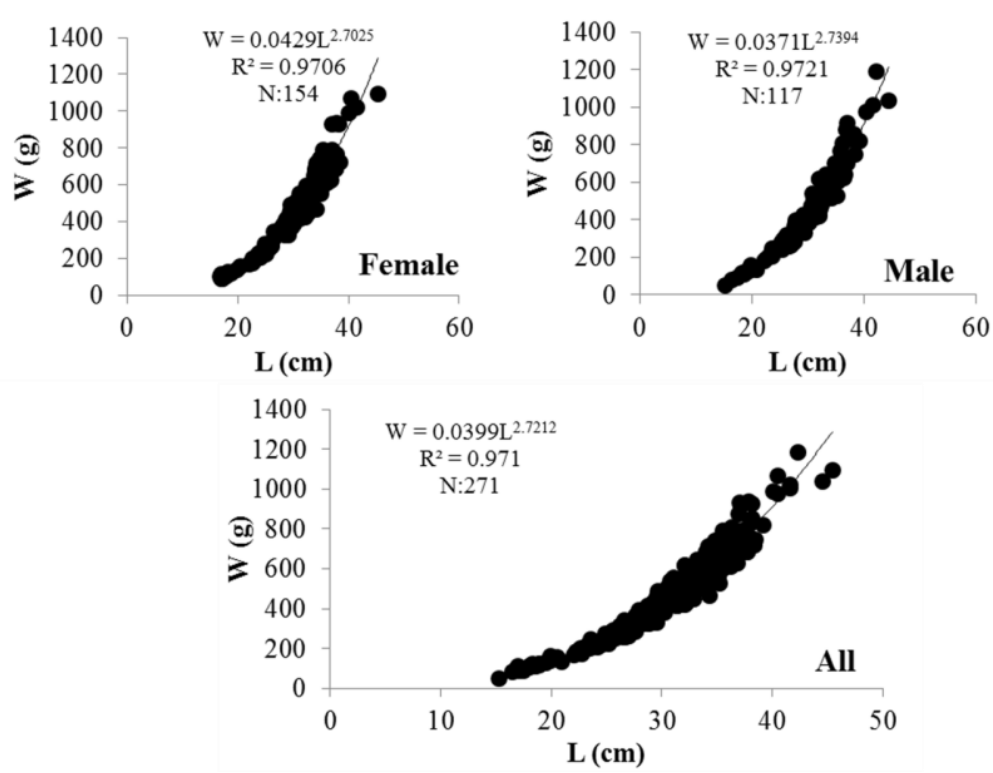

Figure 4. Total length-weight relationship in Diplodus puntazzo 
We calculated the total mortality rate $(Z)$ as 0.560 by using the survival rate $(S)$ with a value of 0.571 . The natural mortality rate (M) was calculated from the growth parameters of $D$. puntazzo and the temperature at the sampling depth. The average $( \pm S D)$ depth of sampling area was $15 \pm 10 \mathrm{~m}$, where the average annual temperature was $15 \pm 6^{\circ} \mathrm{C}$ for these depths. Based on available data, the natural mortality rate was calculated as $\mathrm{M}=0.501$ and the fishing mortality rate $(\mathrm{F}=\mathrm{Z}-\mathrm{M})$ was computed as 0.059 .

\section{Reproduction}

GSI values of female and male samples were estimated monthly. When the monthly GSI values of the females were examined, it was observed that the values started to rise from August and reached its highest in September. The highest GSI value for the females was estimated at 6.83, in September, and the lowest was estimated at 0.31 , in December. The highest GSI value for the males was 7.635 and development showed parallelism with females (Figure 6).

\section{Fecundity}

The smallest individual that was examined for the fecundity was $25.2 \mathrm{~cm}$ in length and $259.93 \mathrm{~g}$ in weight. The largest individual was 33.9 in length and $650.37 \mathrm{~g}$ in weight. Length and fecundity, weight - fecundity, length and egg diameter, gonad weight and egg diameter relationship were given Figure 7 . The lowest egg count was estimated 82650.0 and the highest as 887259.5 eggs. The average fecundity of the examined individuals for fecundity was estimated as $428331.6 \pm 208442.2$ eggs. The average relative fecundity was estimated as 14695.4 egg/1g (8305.0-22727.2) (Table 6).

Though no significant relationship was found between egg diameter with length $(r=0.169)$ and weight $(r=0.321)$, there was a significant relationship between egg count with length $(r=0.502)$ and weight $(r=656)$.

Table 4. Diplodus puntazzo species length-weight relationship by age

\begin{tabular}{lccc}
\hline Age & $\mathrm{N}$ & Avg.L $(\mathrm{cm})$ & Avg.W (g) \\
\hline 0 & 18 & 17.87 & 106.11 \\
1 & 45 & 24.85 & 252.83 \\
2 & 108 & 29.73 & 418.09 \\
3 & 45 & 33.14 & 546.29 \\
4 & 28 & 35.19 & 653.21 \\
5 & 12 & 36.76 & 747.04 \\
6 & 9 & 37.81 & 793.27 \\
7 & 3 & 38.43 & 750.28 \\
8 & 5 & 41 & 1045.29 \\
9 & 3 & 43.83 & 1050.69 \\
\hline Total & 276 & &
\end{tabular}

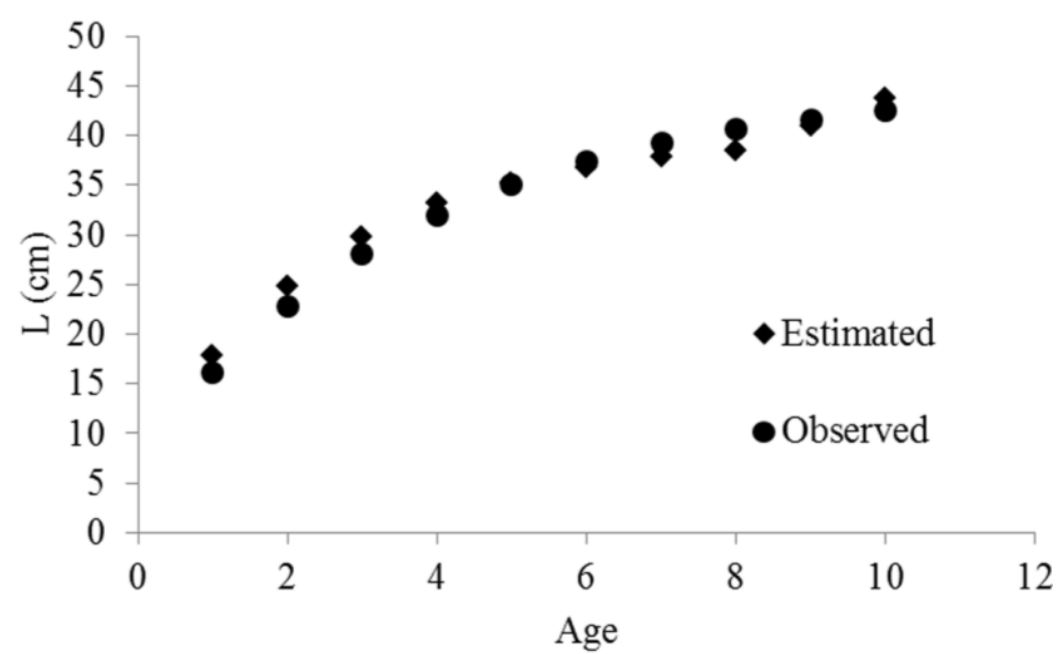

Figure 5. Age-total length relationship in Diplodus puntazzo the southern Black Sea.

Table 5. The von Bertalanffy Growth parameters and growth performance

\begin{tabular}{cccccc}
\hline $\mathrm{L}_{\infty}$ & $\mathrm{k}$ & $\mathrm{t}_{0}$ & $\mathrm{~b}$ & $\phi^{\prime}$ & $\mathrm{L}_{\mathrm{t}}=\mathrm{L}_{\infty}\left[1-\mathrm{e}^{\left(-\mathrm{k}\left(\mathrm{t}-\mathrm{t} \mathrm{o}_{0}\right)\right.}\right]$ \\
\hline 45.1 & 0.2656 & -1.6587 & 2.7212 & 2.73 & $\mathrm{~L}(\mathrm{t})=45.1\left[1-\mathrm{e}^{-0.2656(\mathrm{t}+1.6587)}\right]$ \\
\hline
\end{tabular}




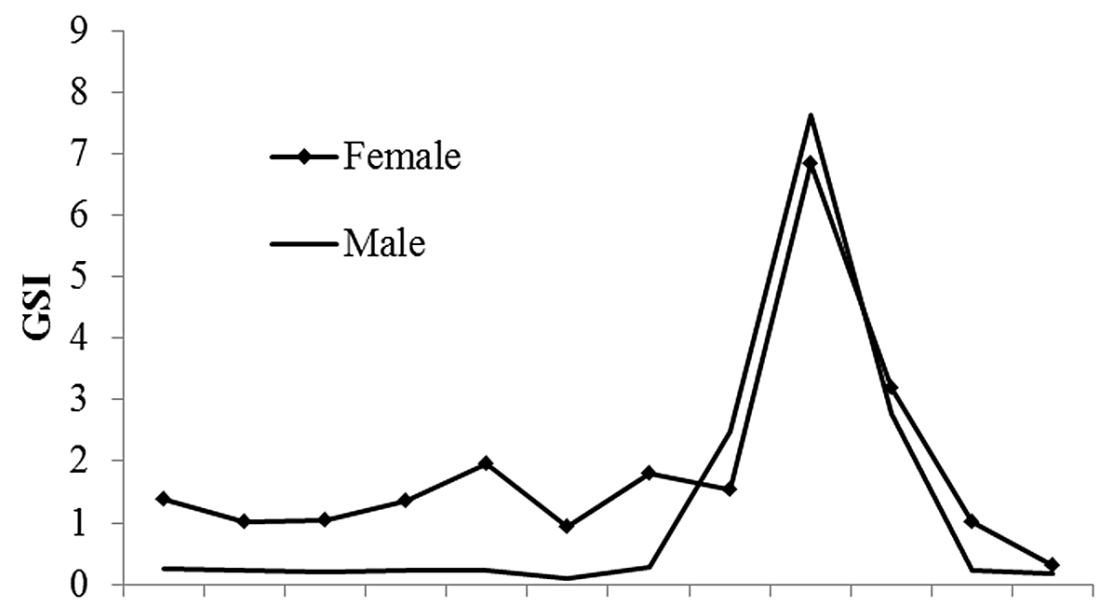

Jan. Feb. Mar. Apr. May Jun. Jul. Agu. Sep. Oct. Nov.Dec.

Figure 6. Monthly distribution of gonadosomatic index (GSI) values of the Diplodus puntazzo by sex.

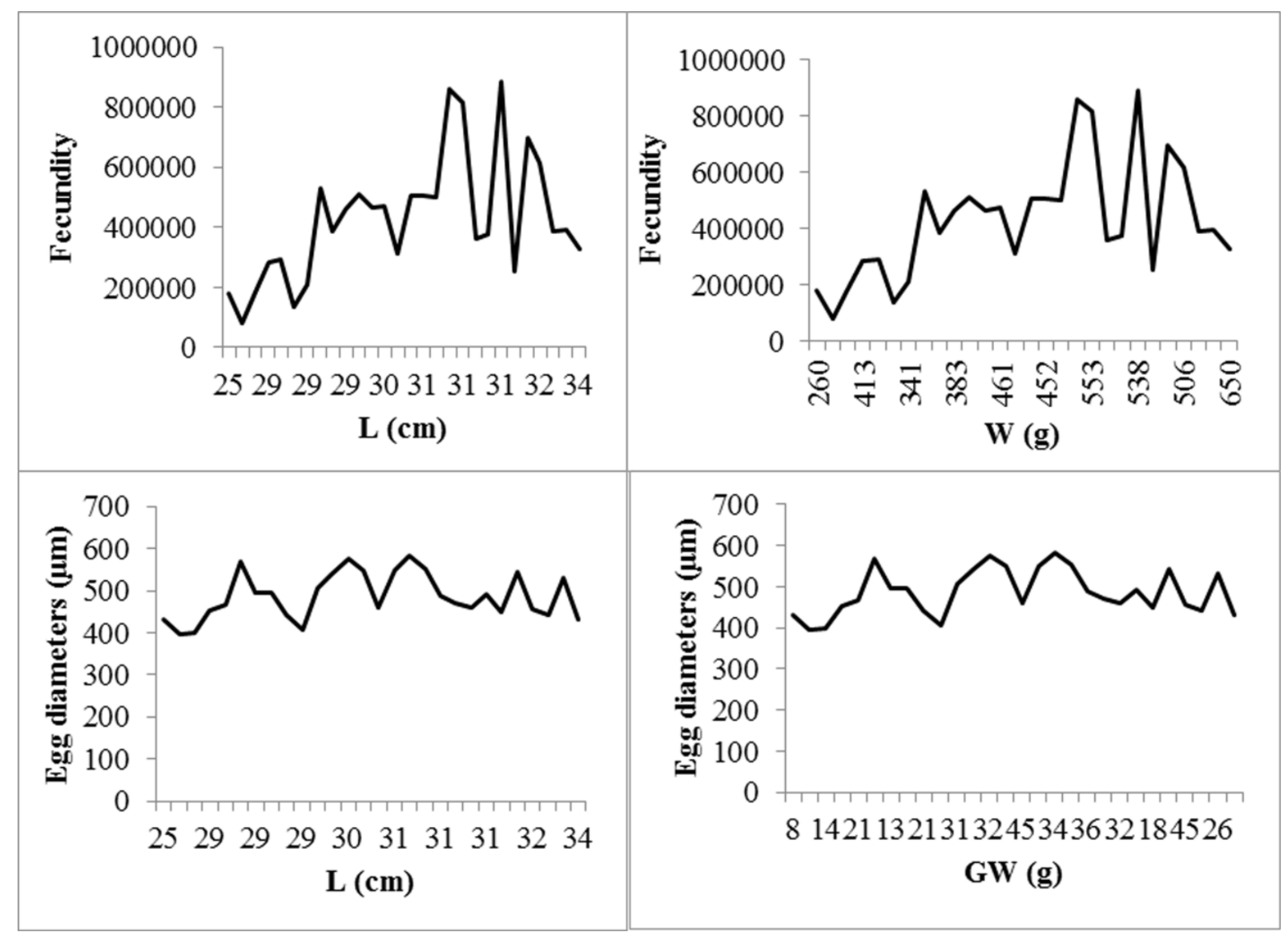

Figure 7. L - fecundity, $\mathrm{W}$ - fecundity, L - egg diameter and GW - egg diameter relationship

Table 6. Egg diameters and counts of September

\begin{tabular}{lcccc}
\hline \multicolumn{5}{c}{ Egg diameter $(\boldsymbol{\mu m})$} \\
\hline \multirow{5}{*}{ September } & Avg. & SE & Min. & Max. \\
\hline \multicolumn{5}{c}{ Avg. egg number (number/1gr) } \\
\hline September & 486.83 & SE & 243.30 & 802.6 \\
\hline
\end{tabular}




\section{Condition Factor}

The condition factor determines the changes in a living organism due to seasonal or monthly diet. In this study, sharpsnout seabream' monthly condition factors of female, male and overall individuals were estimated (Figure 8). The average condition factor was estimated at 1.55, and the lowest was in February (1.378) and the highest was in July (1.712).

\section{Discussion}

Many fish populations sex ratio is expected to be very close to 1:1 even though factors such as differences between each sex' mortality rate due to fisheries or natural causes, migratory behavior for reproductive purposes, differences between each sex in terms of maturity age or size, and different sex and size group individuals inhabiting different habitats (Nikolskii, 1980). During the study a total of 276 sharpsnout seabream individuals were obtained, $55.80 \%$ (154) identified as female, $42.39 \%$ (117) as male, and $1.18 \%$ (5) as hermaphrodite. The sex ratio was estimated to be 1:1.32. The study conducted by Chaouch et al. (2013) estimated the sex ratio as 1:2.8, Mouine et al. (2006) as $1: 4$ and Pajuelo et al. (2008) as 1:2.03. Studies have shown that there are more females in the population. As a result of hermaphroditism, it is known that individuals turn in to females after reaching the first maturity length. Therefore, the majority of female individuals in the population should be considered as expected. Pajuelo et al. (2008) reported twice more (3.59\%) hermaphrodite individuals, and Chaouch et al. (2013) reported that in the Mediterranean Sea hermaphrodite individuals are between $14-21 \mathrm{~cm}$ in length. In this study hermaphrodite, individuals were measured larger (22.7$25.6 \mathrm{~cm}$ ). In a study conducted by Pajuelo et al. (2008) reported even larger sizes from Canary Islands (26-46 $\mathrm{cm})$. Statistically, no difference was found between male average length $(30.3 \mathrm{~cm})$ and female' average length $(30.5 \mathrm{~cm})(\mathrm{P}<0.05)$. Pajuelo et al. (2008) has also did not report any relation between average lengths of each sex.

The maximum length and weight data are given in Table 7. Though Fischer et al. (1987) reported that the species maximum length can reach up to $60 \mathrm{~cm}$, in an experimental study from the Adriatic Sea by Kraljević et al. (2007) the maximum length only reached to $46.7 \mathrm{~cm}$. The maximum length in this study was measured as 45.4 $\mathrm{cm}$. A study conducted from the Black Sea by Aydın and Sağlam (2019) reported another large individual as 41.6 $\mathrm{cm}$ in length and $1007.2 \mathrm{~g}$ in weight.

Domínguez - Seoane et al. (2006) reported oldest age as 10 from Canary Islands, and Kraljević et al. (2007) from the Adriatic Sea reported age 18 and identified the species as a long-living species. Kraljević et al. (2007)

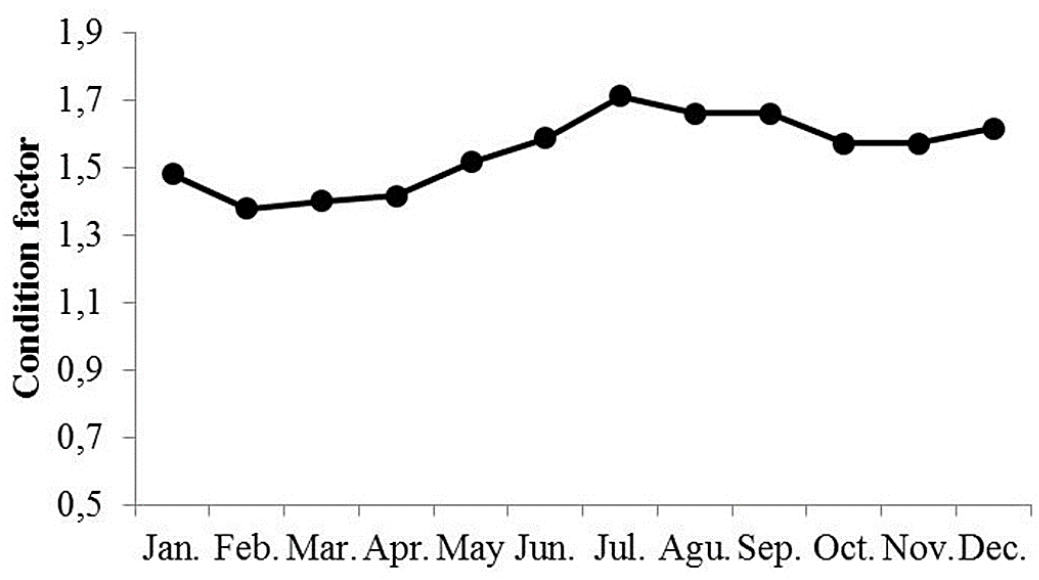

Figure 8. Monthly distribution of the Condition factor for Diplodus puntazzo.

Table 7. The maximum length and weight reported by other studies from the Black Sea, Aegean Sea, Sea of Marmara, Mediterranean Sea and the Adriatic Sea

\begin{tabular}{lcccc}
\hline References & Regions & $\mathrm{N}$ & $\mathrm{L}_{\max }(\mathrm{cm})$ & $\mathrm{W}_{\max }(\mathrm{g})$ \\
\hline Karakulak et al. (2006) & Aegean Sea & 7 & 25.2 & - \\
Özaydin et al. (2007) & Aegean Sea & 27 & 21.4 & - \\
Kraljević et al. (2007) & Adriatic & 630 & 46.7 & 1545.00 \\
Kapiris \& Klaoudatos (2011) & Aegean Sea & 29 & 23.9 & 209.00 \\
Chaouch et al. (2013) & Mediterranean & 490 & 26.1 & 230.83 \\
Altin et al. (2015) & Aegean Sea & 87 & 24.5 & 209.80 \\
Öztekin et al. (2016) & Marmara & 2 & 32.3 & 535.00 \\
Kara et al. (2018) & Aegean Sea & 61 & 13.5 & 41.30 \\
Aydın \& Sağlam (2019) & Black Sea & 11 & 41.6 & 1007.2 \\
This study & Black Sea & $\mathbf{2 7 6}$ & $\mathbf{4 5 . 4}$ & $\mathbf{1 1 8 6 . 4 8}$ \\
\hline
\end{tabular}


reported the largest individual from the eastern Adriatic Sea as $46.7 \mathrm{~cm}$ and $1545 \mathrm{~g}$ in weight. As mentioned before the largest individual in this study was $45.5 \mathrm{~cm}$ $1186.48 \mathrm{~g}$ and is the largest reported individual from the Black Sea, Sea of Marmara, Aegean Sea and the eastern Mediterranean Sea, which is also the second-largest reported individual for the whole Mediterranean Sea. The other studies conducted from the Black Sea, Aegean Sea, Sea of Marmara, Mediterranean Sea and the Adriatic Sea is given in Table 7.

Species von Bertalaffy growth parameters reported by other studies from different areas are presented in Table 8.

D. puntazzo is a native species for the Black Sea (Russell et al., 2014) and it is observed that its population increases day by day. But there are no studies on the species population in the Black Sea.

In recent years a large part of the coastal area of the Southern Black Sea has been filled up for road and airport construction as well as land acquisitions. Despite the negative impact these filled areas have on coastal marine habitats, it is thought that this development had a positive impact on some demersal species (shi drum, brown maegre, sharpsnout seabream, sea bream, seabass, striped sea bream, etc.) in terms of population increase. Lately, a noticeable increase has been observed on such species (Aydin \& Sözer, 2016). Since the habitat structure of the Black Sea is limited in algae communities and rocky areas, unlike the Mediterranean and Aegean Sea, does not allow the shelter of such fish especially for small individuals. These species juveniles inhabit coastal algae communities and rocky habitats, and as they grow migrate to deeper waters (Fischer et al., 1987). It is thought that filled coastal areas provide suitable habitats for these species' juveniles. Petrakis \& Stergiou (1997), within the scope of the European Union, identified this species legal length as $15 \mathrm{~cm}$ (age 3). In addition, in a study by Chaouch et al. (2013) reported that the species female reaches sexual maturity at $16.43 \mathrm{~cm}$, and males reach $16.09 \mathrm{~cm}$ which corresponds to age 3 . Mouine et al. (2006) identified this length as $21.55 \mathrm{~cm}$, Pajuelo et al. (2008) identified this length for males as $28.1 \mathrm{~cm}$ and for females as $29.2 \mathrm{~cm}$, Cetinić et al. (2002) estimated for males as $21.8 \mathrm{~cm}$ and for females as $22.6 \mathrm{~cm}$. All the individuals that were obtained during this study are above the legal length identified by the European Union and most are larger than their first maturity length. There is no data on this species legal catch length in our country.

In this study, it was found that the species spawning starts in August and continues till November, but peaks in September. In other studies, conducted on species spawning has reported similar results (Table 9).

Again, Papadaki et al. (2008) reported sharpsnout seabreams spawning period accruing at 21-18.5 다으 September till December, and peak in October.

In this study, the relative fecundity in September was estimated to be14695.4 egg/1g (8305.0 - 22727.2). Hernandez et al. (2003) estimated the fecundity to reach its peak in September with 2.4 million/kg eggs.

In this study, the condition factor was estimated at 1.55 (min:1.378 max:1.712). Hernandez et al. (2003), reported the condition factor minimum 1.83 and 2.51 maximum. The difference between both studies can be the result of study area difference.

Table 8. Similar studies von Bertalanffy growth parameters $(L \infty, k, t 0)$ and growth performance index $\left(\phi^{\prime}\right)$

\begin{tabular}{lccccc}
\hline $\mathrm{L}_{\infty}$ & $\mathrm{K}$ & $\mathrm{t}_{0}$ & $\mathrm{~b}$ & $\phi^{\prime}$ & References \\
\hline $\mathbf{4 5 . 1 0}$ & $\mathbf{0 . 2 6 5 6}$ & $\mathbf{- 1 . 6 5 8 7}$ & $\mathbf{2 . 7 2 1}$ & $\mathbf{2 . 7 3}$ & This study \\
45.28 & 0.191 & -0.306 & 3.001 & --- & Kraljević et al. (2007) \\
54.10 & 0.182 & -2.531 & 2.590 & --- & Domínguez-Seoane et al. (2006) \\
28.39 & 0.183 & -1.652 & --- & Chaouch et al. (2013) \\
23.19 & 0.472 & -0.248 & --- & Bradai et al. (1998) \\
\hline
\end{tabular}

Table 9. Sharpsnout seabream spawning periods from different locations

\begin{tabular}{lcc}
\hline Season & Regions & References \\
\hline Oct.-Dec. & Cyprus & Georgiou and Stephano (1995) \\
Oct.-Nov. & Cyprus & Marangos (1995) \\
Sep.-Oct. & Italy & Micale et al. (1996) \\
Oct.-Nov. & Tunisian & Bradai (2000) \\
Agu.-Oct. & Spain & Hernandez et al. (2003) \\
Oct.-Dec. & Italy & Lahnsteiner and Paternello (2004) \\
Sep. & Tunisian & Mouine et al. (2006) \\
Sep.-Feb. & Canary Islands & Pajuelo et al. (2008) \\
Sep.-Dec. & Greece & Papadaki et al. (2008) \\
Oct.-Nov. & Tunisian & Chaouch et al. (2013) \\
Sep. & Black Sea & This study
\end{tabular}




\section{Conclusions}

Sharpsnout seabream, even though is a native species in the Mediterranean Sea, there is limited literature on its population. More studies should be conducted on such an economically valuable species population. Even though this study provides important information by being the most comprehensive work done for all our seas, and it is the first study for the Black Sea, more detailed studies should be carried out on this species. It is especially important for the studies to focus on matters such as nutritional characteristics and presence in ecosystem, breeding areas and first maturity length for the sustainability of the species. In this context, the necessary data needed by the ministry should be provided and the legal regulations should be completed as soon as possible.

\section{Ethical Statement}

This study was conducted in accordance with ethics committee procedures of animal experiments.

\section{Funding Information}

This project was supported by Scientific Research Coordination Department of Ordu University with a code B-1914.

\section{Author Contribution}

Author MA designed the study, ÇÖ wrote the first draft of the manuscript, and both authors conducted field work and lab work together. Both authors read and approved the final manuscript.

\section{Conflict of Interest} interest.

The authors declare that there is no conflict of

\section{Acknowledgements}

I would like to thank Scientific Research Coordination Department of Ordu University for their financial support.

\section{References}

Altın, A., Ayyıldız, H., Kale, S., \& Alver, C. (2015). Length-Weight Relationships of 49 Fish Species from Shallow Waters of Gökçeada Island, Northern Aegean Sea. Turkish Journal of Zoology, 39, 1-5. https://doi.org/10.3906/zoo-141215

Aydın, M., \& Sağlam, H. (2019). First report of predation on egg capsules of invasive Rapa whelk by sharpsnout seabream (Diplodus puntazzo) in the Black Sea. Thalassas: An International Journal of Marine Sciences, 35(1), 319-321. https://doi.org/10.1007/s41208-019-0124-3.

Aydın, M., \& Sözer, A. (2016). Presence of the Gilthead
Seabream in the Black Sea. Turkish Journal of Maritime and Marine Sciences, 2(2), 49-55.

Bargelloni, L., Alarcon, J.A., Alvarez, M.C., Penzo, E., Magoulas, A., Palma, J., \& Patarnello, T. (2005). The AtlanticMediterranean transition: discordant genetic patterns in two seabream species, Diplodus puntazzo (Cetti) and Diplodus sargus (L.). Molecular phylogenetics and evolution, 36(3), 523-535.

https://doi.org/10.1016/j.ympev.2005.04.017

Boglione, C., Giganti, M., Selmo, C., \& Cataudella, S. (2003). Morphoecology in larval fin-fish: a new candidate species for aquaculture, Diplodus puntazzo (Sparidae). Aquaculture International, 11, 17-41. https://doi.org/10.1023/A:1024119032359

Bradai, M.N. (2000). Diversité du peuplement ichtyque et contribution à la connaissance des Sparidés du golfe de Gabès (PhD dissertation). Thèse Doctorat État, Univ Sfax, Faculté des Sciences de Sfax Tunisie, $600 \mathrm{p}$.

Bradai, M.N., Ghorbel, M., Jarboui, O., \& Bouain, A. (1998). Croissance de trois espèces de spari dés: Diplodus puntazzo, Diplodus vulgaris et Spon dylosoma can th arusdu gol fe de Gabès (Tunisie). In: Lleonart J. (ed.). Dynamique des populations marines. Zaragoza: CIHEAM,. p. 51 -56 (Cahiers Options Méditerranéennes; n 35).

Cetinić, P., Soldo, A., Dulčić, J., \& Pallaoro, A. (2002). Specific method of fishing for Sparidae species in the eastern Adriatic. Fisheries Research, 55, 131-139. https://doi.org/10.1016/S0165-7836(01)00299-5

Chaouch, H., Hamida, O.B.A.B.H., Ghorbel, M., \& Jarboui, O. (2013). Diet composition and food habits of Diplodus puntazzo (Sparidae) from the Gulf of Gabès (Central Mediterranean). Journal of the Marine Biological Association of the United Kingdom, 93(8), 2257-2264. https://doi.org/10.1017/S0025315413000805

Chugunova, L.P. (1963). Age Growth Studies in Fish National Science Foundation, 132p, Washington.

Çoban, D., Suzer, C., Yıldırım, S., Saka, Ş., \& Fırat, K. (2012). Morphological development and allometric growth of sharpsnout seabream (Diplodus puntazzo) larvae. Turkish Journal of Fisheries and Aquatic Sciences, 12, 883-91. 10.4194/1303-2712-v12_4_16

Domínguez-Seoane, R., Pajuelo, J.G., Lorenzo, J.M., \& Ramos, A.G. (2006). Age and growth of the sharpsnout seabream Diplodus puntazzo (Cetti, 1777) inhabiting the Canarian archipelago, estimated by reading otoliths and by back calculation. Fisheries Research, 81(2-3), 142-148. https://doi.org/10.1016/j.fishres.2006.08.001

Favaloro, E., \& Mazzola, A. (2003). Meristic variation and skeletal anomalies of wild and reared sharpsnout seabream juveniles (Diplodus puntazzo, Cetti, 1777) off coastal Sicily, Mediterranean Sea. Aquaculture Research, 34, 575-79. https://doi.org/10.1046/j.1365-2109.2003.00857.x

Favaloro, E., \& Mazzola, A. (2006). Meristic character counts and incidence of skeletal anomalies in the wild Diplodus puntazzo (Cetti, 1777) of an area of the south-eastern Mediterranean Sea. Fish Physiology and Biochemistry, 32, 159-66. https://doi.org/10.1007/s10695-006-0008-3

Fischer, W., Bauchot, M.L., \& Schneider, M. (1987). Fiches FAO d'identification pour les besoins de la peche revision 1. Mediterranee et mer Noire. Zone de peche 37, vol. 2: Vertebres, Rome, FAO, pp. 761-1530.

Georgiou, G., \& Stephanou, D. (1995). Contribution to the 
study of maturation and spawning problems of the sharpsnout seabream Puntazzo puntazzo. In Lasram M Ed, Marine Aquaculture Finfish Species Diversification. Centre International Hautes Études Agronomiques Méditerranéennes, Zaragoza, 47-50.

Hernandez, M.D., Egeaa, M.A., Ruedaa, F.M., Martýnez, F.J., \& Garcýa, B.G. (2003). Seasonal condition and body composition changes in sharpsnout seabream (Diplodus puntazzo) raised in captivity. Aquaculture, 220, 569-580. https://doi.org/10.1016/S0044-8486(02)00638-5

Jardas, I. (1996). Jadranska ihtiofauna. Školska knjiga: Zagreb. 553 pp. (in Croatian).

Kapiris, K., \& Klaoudatos, D. (2011). Length-Weight Relationships for 21 Fish Species Caught in the Argolikos Gulf (central Aegean Sea, eastern Mediterranean). Turkish Journal of Zoology, 35, 717-723. https://doi.org/10.3906/zoo-1003-122

Kara, A., Sağlam, C., Acarli, D., \& Cengiz, Ö. (2018). Lengthweight relationships for 48 fish species of the Gediz estuary, in Izmir Bay (Central Aegean Sea, Turkey). Journal of the Marine Biological Association of the United Kingdom, 98(4), 879-884. https://doi.org/10.1017/S0025315416001879

Karakulak, F.S., Erk, H., \& Bilgin, B. (2006). Length-Weight Relationships for 47 Coastal Fish Species from the Northern Aegean Sea, Turkey. Journal of Applied Ichthyology, 22, 274-278. https://doi.org/10.1111/j.1439-0426.2006.00736.x

King, M. (1995). Fisheries Biology, Assessment and Management, Osney Mead, Oxford OX2 OEL, England.

Kraljević, M., Matić-Skoko, S., Dulčić, J., Pallaoro, A., Jardas, I., \& Glamuzina, B. (2007). Age and growth of sharpsnout seabream Diplodus puntazzo (Cetti, 1777) in the eastern Adriatic Sea. Cahiers de Biologie Marine, 48(2), 145-154.

Lahnsteiner, F., \& Paternello, P. (2004). Biochemical egg quality determination in the gilthead seabream, Sparus aurata: reproducibility of the method and its application for sharpsnout seabream, Puntazzo puntazzo. Aquaculture, 237, 433-442.

https://doi.org/10.1016/j.aquaculture.2004.04.016

Marangos, C. (1995). Larviculture of the sheepshead bream, Puntazzo puntazzo (Gmelin 1789) (Pisces, Sparidae). Cah Options Médit, 16, 41-46.

http://om.ciheam.org/article.php?IDPDF=96605563

Micale, V., Perdichizzi, F., \& Basciano, G. (1996). Aspects of reproductive biology of the sharpsnout seabream Diplodus puntazzo (Cetti, 1777): I. Gametogenesis and gonadal cycle in captivity during the third year of life. Aquaculture, 140, 281-291. https://doi.org/10.1016/0044-8486(95)01179-X

Mouine, N., Chakroun-Marzouk, N., \& Ktari, M.H. (2006). Cycle sexuel de D. puntazzo (Cetti, 1777) du golfe de Tunis. Buletin de l'Institut National des Sciences et Technologies de la Mer, 10, 85-88.

Mouine, N., Francour, P., Ktari, M.H., \& Chakroun-Marzouk, N. (2012). Reproductive biology of four Diplodus species Diplodus vulgaris, $D$. annularis, $D$. sargus sargus and $D$. puntazzo (Sparidae) in the Gulf of Tunis (central Mediterranean). Journal of the Marine Biological Association of the United Kingdom, 92, 623-631. https://doi.org/10.1017/S0025315411000798

Nikolskii, G.V. (1980). Theory of Fish Population Dynamics as the Biological Background for Ration Exploitation and Management of Fisheries Resources. Bishen Singh
Mahendra Pal Singh Dehradun India and Otto Koeltz Science Publishers Koenigstein, W. Germany, 326 pp.

Özaydın, O., Uçkun, D., Akalın, S., Leblebici, S., \& Tosunoğlu, Z. (2007). Length-Weight Relationships of Fishes Captured from Izmir Bay, Central Aegean Sea. Journal of Applied Ichthyology, 23, 695-696. https://doi.org/10.1111/j.1439-0426.2007.00853.x

Öztekin, A., Özekinci, U., \& Daban, İ.B. (2016). Length-Weight Relationships of 26 Fish Species Caught by Longline from the Gallipoli Peninsula, Turkey (Northern Aegean Sea). Cahiers de Biologie Marine, 57, 175-178.

Pajuelo, J.G., Lorenzo, J.M., \& Domínguez-Seoane, R. (2008). Gonadal development and spawning cycle in the digynic hermaphrodite sharpsnout seabream Diplodus puntazzo (Sparidae) off the Canary Islands, northwest of Africa. Journal of Applied Ichthyology, 24, 68-76. https://doi.org/10.1111/j.1439-0426.2007.01010.x

Palma, J., \& Andrade, J.P. (2002). Morphological study of Diplodus sargus, Diplodus puntazzo and Lithognathus mormyrus (Sparidae) in the Eastern Atlantic and Mediterranean Sea. Fisheries Research, 57, 1-8. https://doi.org/10.1016/S0165-7836(01)00335-6

Papadaki, M., Papadopoulou, M., Siggelaki, I., \& Mylonas, C.C. (2008). Egg and sperm production and quality of sharpsnout seabream (Diplodus puntazzo) in captivity. Aquaculture, 276, 187-197.

https://doi.org/10.1016/j.aquaculture.2008.01.033

Pauly, D. (1980). On the interrelationships between natural mortality, growth parameters, and mean environmental temperature in 175 fishstocks. ICES Journal of Marine Science, 39(2), 175-192.

Pauly, D. (1984). Fish population dynamics in tropical water: a manual for use with programme calculators. ICLARM Studies and Reviews 8: 325 pp.

Petrakis, G., \& Stergiou, K.I. (1997). Size selectivity of diamond and square mesh codends for four commercial Mediterranean fish species. ICES Journal of Marine Science, 54, 13-23.

https://doi.org/10.1006/jmsc.1996.0172

Ricker, W.E. (1975). Computation and Interpretation of Biology Statistics of Fish Populations. Bulletin of the Fisheries Research Board of Canada, 191, 382.

Russell, B., Pollard, D., \& Carpenter, K.E. (2014). Diplodus puntazzo. The IUCN Red List of Threatened Species. http://dx.doi.org/10.2305/IUCN.UK.2014-3.

Sparre, P., \& Venema, S.C. (1992). Introduction to Tropical Fish Stock Assessment. Part I. Manual. FAO Fisheries Technical Paper No.306, 376p.

TUIK, (2018). Turkish fisheries statistics. 60p. Ankara.

Ventura, D., Lasinio, G.J., \& Ardizzone, G. (2015). Temporal partitioning of microhabitat use among four juvenile fish species of the genus Diplodus (Pisces: Perciforms, Sparidae). Marine Ecology, 36(4), 1013-32. https://doi.org/10.1111/ maec.12198.

Vinagre, C., Cabral, H.N., \& Costa, M.J. (2010). Relative importance of estuarine nurseries for species of the genus Diplodus (Sparidae) along the Portuguese coast. Estuarine, Coastal, and Shelf Science, 86, 197-202. https://doi.org/10.1016/j.ecss.2009.11.013

Yıldırım, S., Çoban, D., Süzer, C., Firat, K., \& Saka, Ş. (2014). Skeletal deformities of cultured sharpsnout seabream (Diplodus puntazzo) larvae during early life development. Ankara Üniversitesi Veteriner Fakültesi Dergisi, 61, 267-73. 